\title{
DIFERENTES FORMAS DE REPETIÇÃO NO ATENDIMENTO LÚDICO
}

Joyce Garbosa de Azevedo ${ }^{1}$, Fabio Camargo Bandeira Villela ${ }^{2}$

${ }^{1}$ Graduanda em Pedagogia na Universidade Estadual Paulista (UNESP), campus de Presidente Prudente. E-mail: joyce98ga@hotmail.com. Bolsa do Núcleo de Ensino - PROGRAD - UNESP/ICSB

${ }^{2}$ Doutor pelo Programa de Pós-Graduação em Educação da Universidade Estadual de Campinas (UNICAMP). Docente do Departamento de Educação da Universidade Estadual Paulista (UNESP), campus de Presidente Prudente. E-mail: fabiocbv@stetnet.com.br

\section{RESUMO}

A criança que brinca tem a possibilidade de expandir sua personalidade e solucionar conflitos próprios do desenvolvimento emocional. A FCT/UNESP desenvolve um projeto denominado Desenvolvimento de atividades lúdicas para alunos com dificuldades emocionais, que visa atender, por meio da brincadeira, crianças de uma escola da rede municipal com dificuldades em seu desenvolvimento emocional. Com base na teoria de Winnicott, o artigo investiga e distingue duas repetições que envolvem a brincadeira, as quais foram observadas nas atividades lúdicas: durante o brincar e com o estabelecimento de um vínculo, a criança pode simbolizar e elaborar seu conflito através da brincadeira; entretanto, diante de um conflito intenso, a criança pode passar a repetir certa brincadeira ou conduta, compulsivamente, fortalecendo as resistências e aumentando a ansiedade. $\mathrm{O}$ artigo visa fornecer elementos teóricos para subsidiar a compreensão das atividades lúdicas destinadas a auxiliar a criança na elaboração de seus conteúdos psíquicos. Palavras-chave: Winnicott, brincadeira, desenvolvimento emocional, repetição, elaboração.

\section{DIFFERENT FORMS OF REPETITION IN CARE THROUGH PLAY}

\begin{abstract}
The child who plays has the opportunity to expand his personality and solve the conflicts of his emotional development. FCT/UNESP is developing a project called Development of play activities for students with emotional difficulties, which aims, through play, to care for children from a school in the municipal network who have difficulties in their emotional development. This article distinguishes two repetitions involving play, observed in play activities, the investigation based on Winnicott's theory: the child can symbolize and interpret his conflict through play as a bond is established; however, in the face of intense conflict, the child may repeat a certain play or compulsive behavior, reinforcing resistances and increasing anxiety. The article seeks to provide theoretical elements to support the understanding of play activities designed to assist the child in the interpretation of his psychological make-up.
\end{abstract}

Keywords: Winnicott, play, emotional development, repetition, elaboration.

\section{INTRODUÇÃO}

O brincar ocupa um lugar central do desenvolvimento sadio do sujeito: quando os processos psíquicos estão se desenvolvendo de forma livre e sadia, com o apoio de um ambiente estável, a brincadeira torna-se prazerosa e favorece o enriquecimento das experiências que formarão a base para a estabilidade do sujeito adulto. Entretanto, é um erro considerar que o desenvolvimento infantil é simples, visto que, durante esse período, a criança enfrenta diversos desafios para conseguir estruturar a própria personalidade. Durante o desenvolvimento 
emocional infantil, os conflitos são intensos e, por isso, muitas vezes são reprimidos pela consciência que busca manter a estabilidade e a segurança do que já fora construído em termos da personalidade.

Esses conflitos, mesmo que inconscientes, frequentemente interferem no decorrer das atividades que a criança realiza e impossibilitam ou dificultam seu avanço para outras fases do desenvolvimento. Dessa forma, é possível que, por meio da brincadeira, a criança venha a elaborar conteúdos que são próprios de algum conflito. Além disso, Winnicott destaca a importância do brincar durante a infância, pois essa atividade possibilita expressão livre e espontânea de conflitos inerentes ao desenvolvimento, bem como a elaboração desses e também amplia e promove uma expansão do self.

Os cuidados e a adaptação ambiental proporcionados à criança em um determinado estágio podem não ter sido suficientes para ela. Nesse caso, por intermédio da brincadeira, a criança tem a possibilidade de estabelecer um vínculo com alguém que lhe proporciona uma estabilidade. Com o decorrer das atividades lúdicas e a confiança estabelecida, a criança pode passar a elaborar esses conflitos por meio da atividade criativa.

O principal objetivo deste trabalho é diferenciar as formas de repetição que acontecem durante a brincadeira infantil: a brincadeira que permite a elaboração dos conflitos e que contribui com o desenvolvimento infantil, e a brincadeira compulsiva, que se distingue da primeira por levar a criança a uma repetição externa e estereotipada que impede a elaboração consciente ou não - dos conflitos próprios do desenvolvimento e, por conseguinte, dificultam a estruturação da personalidade. No decorrer do trabalho, serão apresentados comportamentos atribuídos a um ou outro tipo de brincadeira, além de formas de ajudar a criança que não consegue elaborar conflitos emergentes e apenas repete obstinadamente certos tipos de brincadeira sem a presença de uma simbolização da experiência.

Essas duas formas de repetição puderam ser observadas em um projeto de brinquedoteca escolar do Núcleo de Ensino da FCT/UNESP - campus de Presidente Prudente -, denominado Desenvolvimento de atividades lúdicas para alunos com dificuldades emocionais, destinado ao atendimento de crianças do ensino fundamental de uma escola da rede municipal de Presidente Prudente que apresentavam dificuldades consideráveis em seu desenvolvimento emocional. Sua elucidação teórica permitirá benefícios ao projeto, bem como ao debate sobre contribuições da psicanálise a atividades lúdicas, desenvolvidas no interior de escolas de Educação Infantil e Ensino fundamental.

\section{METODOLOGIA}

O artigo busca a compreensão teórica de dois aspectos que envolvem o brincar: a brincadeira elaborativa e a brincadeira compulsiva. Essas duas formas de brincar, que foram observadas no contexto do projeto de brinquedoteca escolar, com vistas ao atendimento de crianças com dificuldades emocionais, ainda que apresentem um caráter de repetição, possuem uma natureza bastante diversa e com repercussões muito distintas em relação ao desenvolvimento emocional da criança. Para essa investigação, serão buscados elementos teóricos na psicanálise de Winnicott e Freud que permitam tanto a compreensão dessas formas diversas de repetição presentes na brincadeira da criança, como permitam fornecer subsídios para a brinquedoteca escolar com foco em seu desenvolvimento emocional. Portanto, a presente pesquisa terá como método básico a pesquisa bibliográfica, conforme especificado acima, embora as questões tenham sido pensadas a partir do atendimento lúdico de crianças e 
tenha o objetivo de trazer subsídios para tal atendimento.

\section{RESULTADOS}

O brincar, como linguagem própria da criança, tem a função de estabelecer um contato mediado com a realidade externa, possibilitando a expressão de sentimentos de amor, ódio, inveja, gratidão, entre outros, que são sentimentos normais suscitados no processo de amadurecimento e contato com a realidade externa.

O desenvolvimento emocional infantil é repleto de desafios, para que a criança alcance uma personalidade forte e sadia. Dessa forma, o brincar encontra um espaço essencial no decorrer de diferentes estágios. Para Winnicott, o brincar é terapêutico, pois auxilia no desenvolvimento emocional da criança, expansão do self e elaboração de conflitos. Entretanto, analisaremos o brincar no contexto de uma relação com outra pessoa, pessoa essa que esteja disposta a entender, participar e auxiliar a criança a partir das dificuldades que emergem no contexto da realização das atividades lúdicas.

Como suporte teórico a esse objetivo, encontra-se nos textos de Winnicott a ideia de que, por meio de um ambiente livre e lúdico, que estimule a criatividade e uma relação saudável e confiável entre a criança e uma pessoa capaz de lhe fornecer apoio, é possível haver uma elaboração de conteúdos e conflitos não resolvidos no decorrer do processo de desenvolvimento e os quais se não forem elaborados, consequentemente, dificultarão $o$ desenvolvimento de outras partes da personalidade de forma natural e saudável (WINNICOTT, 1975, p. 63).

Podemos dizer que, quando o conflito é muito intenso para tornar-se consciente, a criança pode, por meio da atividade lúdica, lidar com ele em seu inconsciente e, mesmo que o demonstrando de forma indireta durante a atividade, haverá a possibilidade de compreendê-lo em algum nível e, assim, elaborá-lo.

Essa elaboração possível é favorecida quando o vínculo estabelecido por meio da atividade lúdica - ou, em certos contextos, terapêutica - é forte e sentido pela criança como seguro. Dessa forma, a relação transferencial, eventualmente estabelecida, tende a atuar como facilitadora da compreensão de conflitos psíquicos e de sua resolução. Para Freud (1914), "a transferência cria, assim, uma região intermediária entre a doença e a vida real, através da qual a transição de uma para a outra é efetuada", ou seja, com a criação de um vínculo de confiança, a criança estabelece uma relação transferencial e, pela brincadeira, tem a possibilidade de adequada resolução de conteúdos psíquicos que não foram bem entendidos pela criança ou pouco enfrentados no decorrer de seu desenvolvimento.

[...] para manter na esfera psíquica todos os impulsos que este último [o paciente - JGA] gostaria de dirigir para a esfera motora; e comemora como um triunfo para o tratamento $o$ fato de poder ocasionar que algo que $\mathrm{o}$ paciente deseja descarregar em ação seja utilizado através do trabalho de recordar. Se a ligação através da transferência

transformou-se em algo de modo algum utilizável, o tratamento é capaz de impedir o paciente de executar algumas das ações repetitivas mais importantes e utilizar sua intenção de assim proceder, in statu 
nascendi, como material para 0 trabalho terapêutico. (FREUD, 1914, p. 168).

No decorrer da brincadeira criativa, a criança demonstra certos conteúdos psíquicos. Se está às voltas com os desafios impostos pelo complexo de Édipo, é comum a expressão de conteúdos relacionados a esse conflito: a luta entre animais e humanos, brincadeiras que têm como objetivo salvar a princesa de algum monstro ou vilão, por exemplo. Todas as brincadeiras que emergem da atividade lúdica delineiam uma determinada etapa do desenvolvimento infantil, bem como o conflito que a criança está enfrentando. Por meio dessa expressão dos conteúdos ou dessa simbolização e repetição, há tendencialmente um entendimento deles, ainda que em um nível inconsciente, acompanhado da adequada expressão corporal. Uma repressão intensa, entretanto, pode dificultar tanto a elaboração de conflitos, como sua adequada expressão no domínio corporal.

[...] o princípio a ser lembrado é o de que, sempre que um conflito na psique é relativamente consciente, os instintos são manejados por meio de autocontrole; o compromisso entre as exigências do instinto e as da realidade externa ou social ou consciente pode ser construído com o mínimo de prejuízo possível. Por outro lado, onde o conflito entre o impulso e o Ego ideal encontra-se no inconsciente reprimido, as inibições, compulsões e ansiedades resultantes são mais cegas, menos capazes de se adaptar às circunstâncias, e mais danosas para o corpo e suas funções e processos. (WINNICOTT, 1990, p. 43).
Segundo Winnicott (2015, p. 178), podemos dizer que há dois tipos de comportamentos compulsivos - e, nesse sentido, repetitivos de alguma forma - que podem intervir durante o brincar: o primeiro é um "distúrbio do desenvolvimento emocional", que impede o desenvolvimento da criança, ou seja, há uma pausa e, portanto, não há "evolução" no desenvolvimento infantil e, mesmo que a angústia e os medos da criança ainda estejam presentes na atividade criativa, o ego encontra uma forma de proteger-se e manter a sua personalidade íntegra, fazendo-a sentir "mais segura", mesmo que não haja um curso no desenvolvimento. Nesse caso, a repetição é a reapresentação de um elemento do material, reprimido ou não, que o ego busca dominar ou elaborar, mas ainda não alcançou seu intento completamente ou, pelo menos, não o alcançou de modo satisfatório.

A segunda forma de repetição demonstra os esforços que a criança está empenhando para esquivar-se desse material incômodo, pouco dominado por ela e mesmo à custa da estruturação de sua própria personalidade; isso é, trata-se de uma situação mais grave, que apresenta riscos de uma desintegração da personalidade, de uma de psicose que tenda a se desenvolver, ou, no melhor dos casos, a uma repetição obsessiva como defesa de uma desestruturação psicótica.

Nesse segundo caso, há um sentimento extremo de insegurança diante de conteúdos que deveriam ser dominados ou elaborados de modo a contribuir com a aglutinação das partes da personalidade, mas que, devido aos intensos conflitos e sentimentos de ansiedade, tornam-se excessivamente ameaçadores para a criança. Nesse contexto, o brincar torna-se compulsivo e o trabalho de elaboração do ego cede lugar ao seu trabalho de defesa contra conteúdos, sentidos como ameaçadores.

A angústia excessiva conduz à exacerbação da sexualidade e, 
posteriormente, a uma busca compulsiva dessa satisfação, impedindo a brincadeira criativa (WINNICOTT, 2015, p. 162). Podemos compreender, portanto, que, quando a angústia e a ansiedade impedem o decorrer da atividade lúdica, o melhor é interromper a brincadeira da maneira mais natural possível, para que o ego da criança não estabeleça novas defesas ou mesmo recorra a comportamentos patológicos e mais graves. (WINNICOTT, 2015, p. 164, 2)

Semelhante à criança que rouba algo da mãe, a criança que apresenta um ato compulsivo não saberá explicar ou compreender o motivo que a conduz a brincar de tal maneira, ou seja, não há um estado de consciência e entendimento das razões ou mesmo dos conflitos que desencadeiam tais atitudes compulsivas; não há um reconhecimento da causa. Por isso, há necessidade de alguém que compreenda e que se encarregue de ajudar a criança nesse processo.

Desse modo, as situações ou as causas que levam o indivíduo ao comportamento compulsivo e à repetição são, para ele mesmo, desconhecidas, devido às resistências que a consciência impõe como proteção da personalidade ou como forma de evitar sofrimento intenso. Portanto, as forças repressivas que trabalham na proteção da personalidade induzem o sujeito a uma "não consciência", a fim de um reestabelecimento estável dos mecanismos psíquicos e, para haver um desenvolvimento emocional saudável, é necessário que o ambiente terapêutico para o desenvolvimento da brincadeira seja conduzido de forma espontânea, possibilitando uma situação subjetivamente elaborada por meio da brincadeira, de sua expressão simbólica, mas também através da elaboração que eventualmente se dá pelas saídas criativas da criança frente ao conflito o qual pode ser apresentado de modo lúdico, atenuado, quando não deformado ou transfigurado.

Nas palavras de Winnicott, o bom cuidado que deve ser proporcionado à criança "consiste, sobretudo, em oferecer [...] um conjunto de condições consistentes para que ela possa elaborar o que the é específico." (WINNICOTT, 2015, p. 36), ou seja, essas condições proporcionam à criança, que sofre com esse tipo de comportamento, um alívio das tensões geradas pela insegurança nos processos de desenvolvimento psíquicos e, gradativamente, favorecem o sentimento de confiança que se reestabelece, juntamente com o relacionamento saudável entre a realidade interna e externa.

\section{DISCUSSÃO}

Podemos dizer que há duas formas de repetição que ocorrem durante o brincar: uma delas é a brincadeira elaborativa que, com o decorrer do tempo e do estabelecimento de um vínculo, é a forma privilegiada, mediante a qual a criança tornase capaz de elaborar uma situação ou conflito que foi muito intenso. A segunda forma de repetição, diz respeito à brincadeira compulsiva: ao invés da elaboração do conflito, a criança passa a brincar de forma compulsiva, contribuindo com a criação de defesas do ego contra ameaças que poderiam levar à desintegração parcial ou total da personalidade, ou, ao menos, um sofrimento psíquico que o ego julga incapaz de tolerar.

Nesse segundo caso, a repetição tende a impedir ou a dificultar o desenvolvimento da personalidade e da saúde mental do sujeito. Nos dois casos, é necessário um bom manejo da situação e do ambiente. No caso da brincadeira elaborativa, deve prevalecer a continuidade da relação e da estabilidade do ambiente que suporta esse vínculo essencial no decorrer na brincadeira terapêutica. No caso de a brincadeira tornar-se compulsiva e, portanto, alheia a conteúdos simbólicos ou de elaboração, cabe ao discente que acompanha a brincadeira procurar amenizar as angústias que prevalecem e impedem o decorrer da elaboração simbólica e o fluxo das atividades lúdicas e, sobretudo, cuidar para que os 
aspectos destrutivos não prevaleçam nesse processo e a criança sinta-se insegura, principalmente quanto à desestruturação da personalidade ou emergência de impulsos destrutivos em estado puro.

Entretanto, cabe à criança a iniciativa para a construção desse vínculo que tende a ajudá-la na elaboração dos conflitos internos, embora o campo aberto para o livre estabelecimento de vínculos seja constituído ou garantido pelo discente com quem a criança estabelece as atividades lúdicas. Cabe ressaltar que o que distingue o brincar espontâneo do brincar terapêutico é exatamente a compreensão do discente que realiza as atividades junto com a criança, a sobrevivência dessa, a disponibilidade para a escuta e, principalmente, disponibilidade para estabelecer um vínculo com a criança, de forma que ela se sinta segura para iniciar a brincadeira e elaborar seus conflitos.

\section{CONCLUSÃO}

A elaboração dos conflitos internos durante a brincadeira depende de um conjunto de fatores, mas especialmente da criação de um ambiente estável e do comportamento seguro daquele que participa e tem a intenção de ajudar a criança na elaboração daquele ambiente Dessa forma, julga-se necessária a compreensão dos processos que envolvem o desenvolvimento emocional infantil, visto que, através da brincadeira, a criança manifesta e pode elaborar conteúdos que remetam a alguma fase que não foi bem elaborada no desenvolvimento. Com um olhar sensível, o professor, os pais, ou qualquer outra pessoa é capaz de auxiliar a criança na reestruturação de uma estabilidade e, consequentemente, na construção de uma personalidade sadia, mas um conhecimento maior sobre conteúdos e processos internos da criança permitem lidar de forma mais adequada e terapêutica junto à criança, ainda que através da atividade lúdica marcada pela espontaneidade.

É essencial que o indivíduo ao participar da brincadeira terapêutica tenha um olhar sensível acerca das formas elucidadas no decorrer do estudo: o brincar que favorece a elaboração e contribui com o desenvolvimento emocional da criança de forma natural e, o brincar compulsivo que conduz a criança à repetição isenta de elaboração, fortalecendo as defesas psíquicas e aumentando sua angústia diante dos desafios. Como decorrência, quando há o reconhecimento da forma que o brincar assume na atividade lúdica, é possível uma condução dessa atividade, de acordo com as características do brincar, com o objetivo de auxiliar a criança, quando necessário, no processo de seu desenvolvimento emocional. Entender as duas classes de repetição presentes no brincar da criança consiste em um aspecto importante da compreensão da atividade lúdica desenvolvida pela criança e do manejo terapêutico possível de ser desenvolvido no âmbito da própria atividade lúdica compartilhada.

\section{REFERÊNCIAS}

FREUD, S. Recordar, repetir e elaborar (Novas recomendações sobre a técnica psicanalítica II) 1914. In: FREUD, S. Edição Standart Brasileira das Obras Psicológicas Completas de Sigmund Freud, v. XII. Rio de Janeiro: Imago, 2006. p. 159-171.

WINNICOTT, D. W. O Brincar e a Realidade. Rio de Janeiro: Imago, 1975.

WINNICOTT, D. W. Natureza Humana. Rio de Janeiro: Imago, 1990.

WINNICOTT, D. W. A criança e o seu mundo. 6. ed. Rio de Janeiro: LTC, 2015.

Recebido para publicação em: 01/08/2017

Revisado em: 03/09/2017

Aceito em: 06/09/2017 